approx. £119,000 for investigations and consultations. Using a Caldetect ${ }^{\circledR}$ (Preventis, $\mathrm{GmbH}$ ) point of contact FC test, it was estimated that a saving of $£ 89,000$ could be achieved. A pathway for investigating chronic diarrhoea using Caldetect ${ }^{\circledR}$ was designed and implemented in the community (population 150,000) between September 2011-March 2012. (this will be presented). FC results were categorised using manufacturer cut-offs of $<15 \mathrm{ug} / \mathrm{g}, 15-60 \mathrm{ug} / \mathrm{g}$ and $>60 \mathrm{ug} / \mathrm{g}$. Patients with FC results of $15-60$ and $>60$ were deemed to have an inflammatory process and referred to Gastroenterology Clinics. Cost analysis was carried out using the 2010-11 tariffs for the NHS.

Results 142 Caldetect ${ }^{\circledR}$ tests were carried out in Primary Care during this pilot phase. Of these, a negative result $(<15 \mathrm{ug} / \mathrm{g})$ was present in 89 , with 36 tests being $>60 \mathrm{ug} / \mathrm{g}$. 3 tests were at the intermediate level and 14 tests could not be accurately reported. Negative results were managed in primary care as IBS. A monthly cost savings of $£ 6100$ was calculated taking consultation and endoscopy tariffs into account.

Conclusion This pilot study demonstrates the feasibility and cost effectiveness of a Pathway for decision making and a point-of-care faecal calprotectin test in rationalising referrals to Gastroenterologists for chronic diarrhoea.

Disclosure of Interest A. Dhar Speaker bureau with: Shire Pharamceuticals, Warner Chilcott UK, S. Lee: None Declared, H. Borthwick: None Declared, P. Nair: None Declared, C. White: None Declared

\section{PTU-058 ONE YEAR LIKELIHOOD OF RELAPSE IN ULCERATIVE COLITIS (UC) IS PREDICTED BY MUCOSAL APPEARANCE BUT NOT BY FAECAL CALPROTECTIN: DATA FROM THE CODA STUDY OF ONCE DAILY VERSUS THREE TIMES DAILY ASACOL}

doi:10.1136/gutjnl-2013-304907.150

1."A B Hawthorne, ${ }^{2} \mathrm{D}$ Gillespie, ${ }^{3} \mathrm{C}$ Probert. 'Medicine, University Hospital of UK; ${ }^{2}$ SE UK Trials Unit, Cardiff; ' Institute of translational medicine, Liverpool University, Liverpool, UK

Introduction Faecal calprotectin (FC) has become a useful marker of mucosal healing, with studies showing raised levels predictive of relapse $e^{1,2,3}$. These studies did not assess mucosal healing however, so did not compare calprotectin with mucosal appearance as predictors of relapse.

Methods In the CODA (Colitis Once Daily Asacol ${ }^{\circledR}$ ) trial of once daily (OD) Asaco ${ }^{\circledR}$ (three $800 \mathrm{mg}$ tablets) vs one $800 \mathrm{mg}$ tablet taken three times daily (TDS), 213 UC patients in remission for $>4$ weeks, but relapse in the past 2 years, were recruited. Baseline FC (Phical ELISA kit) was collected and rectal sigmoidoscopy (sig) score at baseline, and relapse or 1 year (using the modified Baron score: $0=$ normal; 1 = erythema, decreased vascular pattern; 2 = marked erythema, absent vascular pattern, friability, erosions; 3 = spontaneous bleeding, ulceration). At entry patients had no symptoms of active disease, with a sig score of 0 or 1 . Follow-up was for 1 year or until relapse (symptoms of active disease with a sig score of 2 or 3 ). Demographic factors, concomitant drugs, FC, sig score, CRP, and adherence were evaluated in a Cox regression model of time to relapse.

Results (Shown as median[IOR] unless stated otherwise). Remission duration prior to entry was 6.0 [3-12] months. Disease extent was extensive $(30.0 \%)$, Lt. sided $(54.9 \%)$, proctitis $(13.6 \%)$. At entry FC was $78 \mathrm{mg} / \mathrm{kg}$ stool [23.3-159.4], sigmoidoscopy score 0 (70.9\%), 1 (29.1\%). All were taking mesalazine, and $11.7 \%$ thiopurines. Baseline FC was higher if sig score was 1 (109[38-335]) than if 0 (62 [21-120], $\mathrm{p}=0.001$, but did not differ according to disease extent or medication (including aspirin $(n=18)$ and occasional NSAIDs $(n=6)$. Remission rates at one year were $62 \%$ overall $(68.9 \%$ in OD and $55.5 \%$ in TDS group). Factors associated with time to relapse were explored in a Cox proportional hazards model, with baseline FC dichotomised at $150 \mathrm{mg} / \mathrm{kg}$ stool (as by Costa et al Relapse risk was 2.5 times higher in those with baseline sig score 1 compared to score 0 (95\% CI 1.32-4.76, p = 0.005). Age, concomitant medication, previous duration of remission, disease extent, smoking, trial medication adherence and baseline FC (cut off at $150 \mathrm{mg} / \mathrm{kg}$ stool or as a continuous variable) did not remain in the final model.

Conclusion In this study, sigmoidoscopy appearance at baseline was the sole factor predicting relapse over 1 year of maintenance mesalazine $2.4 \mathrm{~g}$, whereas calprotectin level was not a predictor, perhaps because of wide variability in this group of patients. FC may have more value in measuring relative change in individual patients. Disclosure of Interest A. Hawthorne Grant/Research Support from: CODA study supported by unrestricted grant from Warner Chilcott, D. Gillespie: None Declared, C. Probert: None Declared

\section{REFERENCES}

1. Gisbert IBD 2009; 15:1190.

2. Tibble Gastroenterol 2000; 119:15

3. Costa Gut 2005; 54:364.

\section{PTU-059 ADALIMUMAB THERAPY REDUCES HOSPITALIZATION AND COLECTOMY RATES IN PATIENTS WITH ULCERATIVE COLITIS AMONG INITIAL RESPONDERS}

doi:10.1136/gutjnl-2013-304907.151

1,*B G Feagan, ${ }^{2} \mathrm{~W}$ J Sandborn, ${ }^{3} \mathrm{M}$ Skup, ${ }^{3} \mathrm{M}$ Yang, ${ }^{4} \mathrm{~A}$ Lazar, ${ }^{3} \mathrm{R}$ B Thakkar, ${ }^{3} \mathrm{~J}$ Chao, ${ }^{3} \mathrm{P}$ M Mulani. 'Robarts Research Institute, University of Western Ontario, London, ON, Canada; ${ }^{2}$ UCSD, La Jolla, CA; ${ }^{3}$ AbbVie, Abbott Park, IL, United States; ${ }^{4} A b b V i e$ Deutschland, Ludwigshafen, Germany

Introduction Two double-blind, placebo-controlled trials (ULTRA 1 and 2) revealed that adalimumab (ADA) therapy significantly reduces hospitalisation and non-significantly decreases colectomy rates in patients with moderate to severe ulcerative colitis (UC). ${ }^{1}$

Methods We assessed the effect of an ADA 160/80/40 mg treatment regimen on risk reduction of all-cause and UC-related hospitalisation and colectomy in these 2 trials among initial ADA responders. The pooled dataset included 963 patients (480 ADA, 483 placebo [PBO]). Hospitalization and colectomy events were based on safety reports reviewed by 2 gastroenterologists who were blinded to treatment. Conservatively, hospitalizations from initial ADA non-responders (per Mayo score at Week 8) through Week 8 were counted, but were censored after Week 8 to reflect the clinical practise pattern of continuing treatment in initial ADA responders. Risk and number of hospitalizations were compared between groups using person-year (PY)-based incidence rates (IRs) and Poisson regression, respectively; Z-scores were used to assess statistical differences. ${ }^{2}$

Results $35 \%$ and $34 \%$ reductions in the number of patients hospitalised and number of hospitalizations for any reason, respectively, were observed with ADA therapy vs. $\mathrm{PBO}$ (table, $P<0.05$ for both comparisons). When UC-related hospitalizations were compared, reductions for rate $(50 \%)$ and number $(54 \%)$ of hospitalizations were both statistically significant, too.

Conclusion Initial ADA-responders had a significantly lower risk for UC-related and all-cause hospitalisation compared with $\mathrm{PBO}$. Reduction of all-cause hospitalisation is unique for $\mathrm{ADA}$ compared with any other anti-tumour necrosis factor agent. A non-significantly lower colectomy rate in patients receiving $\mathrm{ADA}$ vs. those receiving $\mathrm{PBO}$ was also observed.

Disclosure of Interest B. Feagan Grant/Research Support from: AbbVie, Consultant for: AbbVie, W. Sandborn Grant/Research Support from: AbbVie, Consultant for: AbbVie, Conflict with: AbbVie, 
Abstract PTU-059 Table

\begin{tabular}{|c|c|c|c|c|c|c|}
\hline \multicolumn{7}{|c|}{ Hospitalization and Colectomy Rates in ULTRA 1 and 2: Week 8 ADA Responders } \\
\hline \multirow[b]{2}{*}{ Patients } & \multicolumn{2}{|l|}{ ADA } & \multicolumn{2}{|l|}{ PBO } & \multirow[b]{2}{*}{ RR (ADA/PBO) } & \multirow[b]{2}{*}{ P-Value } \\
\hline & n/PYs at Risk & $\begin{array}{l}\text { IR } \\
\text { (n/PYs at Risk) }\end{array}$ & n/PYs at Risk & $\begin{array}{l}\text { IR } \\
\text { (n/PYs at Risk) }\end{array}$ & & \\
\hline All-cause hospitalisation & $46 / 260.4$ & 0.18 & $58 / 222.3$ & 0.26 & 0.68 & $.047^{\mathrm{a}}$ \\
\hline UC-related hospitalisation & $29 / 266.5$ & 0.11 & $49 / 223.6$ & 0.22 & 0.50 & $.002^{\mathrm{a}}$ \\
\hline Colectomy & $6 / 271.9$ & 0.02 & $11 / 231.7$ & 0.05 & 0.46 & $.122^{\mathrm{a}}$ \\
\hline Hospitalizations & E/PYs & IR (E/PYs) & E/PYs & IR (E/PYs) & $\mathrm{RR}(\mathrm{ADA} / \mathrm{PBO})$ & \\
\hline All-cause & $55 / 272.7$ & 0.20 & $71 / 232.8$ & 0.31 & 0.65 & $.021^{\mathrm{b}}$ \\
\hline UC-related & $32 / 272.7$ & 0.12 & $59 / 232.8$ & 0.25 & 0.48 & $<0.001 b$ \\
\hline
\end{tabular}

IR, incidence rate; PYs at Risk, time at risk in patient years; $n$, number of patients with event; $E$, total number of events; RR, relative risk.

aZ-score and normal approximations.

'Poisson regression with time offset.

M. Skup Shareholder of: AbbVie, Employee of: AbbVie, M. Yang Shareholder of: AbbVie, Employee of: AbbVie, A. Lazar Shareholder of: AbbVie, Employee of: AbbVie, R. Thakkar Shareholder of: AbbVie, Employee of: AbbVie, J. Chao Shareholder of: AbbVie, Employee of: AbbVie, P. Mulani Shareholder of: AbbVie, Employee of: AbbVie

\section{REFERENCES}

1. Feagan BG, et al. Presentation OP209, UEGW, Stockholm, Sweden. October 22-26, 2011.

2. Miettinen 0. Am J Epidemiol. 1976; 103:226-35

\section{PTU-060 PHENOTYPIC CHARACTERISATION OF INFLAMMATORY BOWEL DISEASE IN SOUTH ASIANS IN THE UNITED KINGDOM-INSIGHTS INTO A SHIFTING LANDSCAPE}

doi:10.1136/gutjnl-2013-304907.152

1."C Boyd, ${ }^{1} \mathrm{~J}$ K Limdi. 'Department of Gastroenterology, Pennine Acute Hospitals NHS Trust, Manchester, UK

Introduction The aetiology of inflammatory bowel disease (IBD) remains elusive. The increasing incidence of IBD in developing countries and immigrant populations appears to outpace what genetic influences alone could instigate. There is a relative dearth of literature on the phenotypic characteristics of South Asian immigrant populations. The aim of our study was to define the clinical phenotype of IBD in South Asians in North-West England.

Methods We conducted a retrospective study of 102 patients of South Asian origin attending IBD clinics at our hospital. Clinical data including demographics, disease characteristics (Montreal classification), treatment and blood results were obtained using electronic case records.

Results Of 106 patients reviewed, 55 were male. The median age was 38 years (range 16-80) and mean disease duration was 9.5 years. Seventy-six patients had ulcerative colitis (UC) and 30 had Crohn's disease (CD). Five patients were current or ex smokers $(4.7 \%)$. Seventeen patients had extra-intestinal manifestations of IBD (16.0\%). Of UC patients 37 had pancolitis, 34 left sided disease and 5 had proctitis. Of patients with $\mathrm{CD}, 3$ had ileal disease, 11 colonic disease and 16 had ileocolonic disease. Five CD patients had stricturing disease, 10 had penetrating disease ( 6 also stricturing) and 15 had non-penetrating, non-stricturing disease. Perianal disease was noted in 3 at diagnosis and in 5 subsequently. Eighty four patients received steroids, topical steroids (31), 5-ASA (99), topical 5-ASA (31), azathioprine (56), 6- mercaptopurine (4), cyclosporine (2), methotrexate (10), infliximab (21) and adalimumab (10). Fifty eight patients received at least one immunomodulatory therapy with the median time to use being 12 months (range 0-276 months). Thirteen patients ( $7 \mathrm{CD}, 3 \mathrm{UC}$ ) required surgery ( 3 total colectomy, 10 subtotal). Mean time to surgery was 4 years (range $0-13$ years). Seventeen patients had disease progression leading to Montreal reclassification (median time 60 months; range 1-216 months).

Conclusion We noted a higher prevalence of UC with predominantly pancolonic disease and a significant proportion of $\mathrm{CD}$ with penetrating or stricturing disease. The majority of patients required immunomodulatory therapy. Epidemiologic insights from such populations may provide further clues in defining an aetiological paradigm for IBD and should form an important area of further research. A case control study exploring differences is underway at our institution.

Disclosure of Interest None Declared

\section{PTU-061 VITAMIN D DEFICIENCY IS WIDELY PREVALENT IN SOUTH ASIAN PATIENTS WITH INFLAMMATORY BOWEL DISEASE}

doi:10.1136/gutjnl-2013-304907.153

1, ${ }^{*} \mathrm{C}$ Boyd, ${ }^{1} \mathrm{~J} \mathrm{~K}$ Limdi. 'Department of Gastroenterology, Pennine Acute Hospitals NHS Trust, Manchester, UK

Introduction There has been resurgent interest in recent years in the pro-hormone vitamin $\mathrm{D}$ in its role and plausible effects on immune regulation and inflammatory bowel disease (IBD). We postulated a wide prevalence of vitamin $\mathrm{D}$ deficiency in South Asian patients with implications for the control of their IBD. The aim of our study was to review vitamin D assessment in a South Asian IBD cohort.

Methods We conducted a retrospective review of 102 South Asian patients attending IBD clinics in our institution. Clinical data including demographics, disease characteristics (Montreal classification) and therapy were obtained from electronic record review. Serum 25-hydroxyvitamin D (25-OHD) concentrations were recorded in all patients tested and in all having serial measurements. Results Of 106 patients reviewed, 55 were male. The median age was 38 years (range 16-80) and mean disease duration was 9.5 years. Seventy-six patients had ulcerative colitis (UC) and 30 had Crohn's disease (CD). Five patients were current or ex smokers (4.7\%). Vitamin D status was assessed in 52 patients (49\%), 26 had serial measurements. Median 25-OHD was 10.25 (range 3.344.4). Fifty one patients had levels $<25 \mathrm{ng} / \mathrm{ml}$ consistent with deficiency and all 52 had insufficient levels $<50 \mathrm{ng} / \mathrm{ml}$. Of the patients with deficiency 35 had UC and 16 had CD. Of the UC patients, 18 had pancolitis, 13 had left sided disease and 4 proctitis. Of the CD patients 5 had penetrating disease and 4 had stricturing disease. Forty-three of the deficient patients had received 